\title{
Purpura Fulminans Associated with Overwhelming Postsplenectomy Infection
}

\author{
Kazuya Sakai ${ }^{1}$ and Akira Kuriyama ${ }^{2}$ \\ Key words: purpura fulminans, overwhelming postsplenectomy infection, diagnosis
}

(Intern Med 56: 241, 2017)

(DOI: 10.2169/internalmedicine.56.7733)

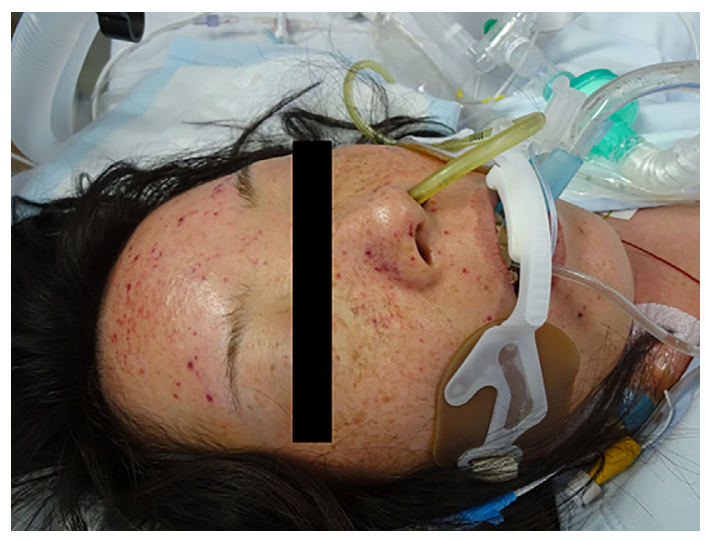

Picture 1.

A 37-year-old Japanese woman was referred to our institute with a 1-day history of a fever and altered mental status. Physical examinations revealed non-palpable purpura on her face, trunk, and extremities (Picture 1, 2). Blood tests revealed marked thrombocytopenia and hypofibrinogenemia. A detailed chart review showed that she had undergone splenectomy 10 years prior and had not been vaccinated against pneumococcus. A lumbar puncture revealed pleocytosis suggesting meningitis, and her blood cultures were positive for Streptococcus pneumoniae. A diagnosis of purpura fulminans (PF) and overwhelming postsplenectomy infection (OPSI) due to pneumococci was established. After therapy with ceftriaxone, she recovered, and the purpura diminished.

Asplenic people are susceptible to severe infections due to encapsulated bacteria, such as $S$. pneumoniae, and develop OPSI, a life-threatening entity (1). Pneumococcus develops both PF and OPSI. PF and OPSI more frequently develop in septic patients with asplenia than in those with intact spleen (2). Physicians need to be aware that purpura may be

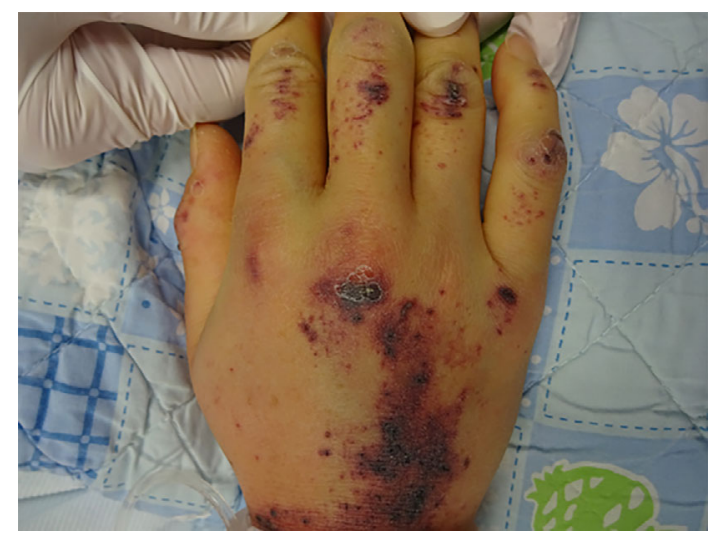

Picture 2.

the only sign of OPSI in asplenic patients.

The authors state that they have no Conflict of Interest (COI).

\section{Acknowledgement}

The author would like to thank Ms. Ryoko Yoshida for editing the pictures.

\section{References}

1. Morgan TL, Tomich EB. Overwhelming post-splenectomy infection (OPSI): a case report and review of the literature. J Emerg Med 43: 758-763, 2012.

2. Theilacker C, Ludewig K, Serr A, et al. Overwhelming postsplenectomy infection: a prospective multicenter cohort study. Clin Infect Dis 62: 871-878, 2016.

The Internal Medicine is an Open Access article distributed under the Creative Commons Attribution-NonCommercial-NoDerivatives 4.0 International License. To view the details of this license, please visit (https://creativecommons.org/licenses/ by-nc-nd/4.0/).

\footnotetext{
${ }^{1}$ Department of Hematology/Oncology, Kurashiki Central Hospital, Japan and ${ }^{2}$ Department of General Medicine, Kurashiki Central Hospital, Japan

Received for publication May 19, 2016; Accepted for publication May 24, 2016

Correspondence to Dr. Akira Kuriyama, akira.kuriyama.jpn@gmail.com

(C) 2017 The Japanese Society of Internal Medicine Journal Website: http://www.naika.or.jp/imonline/index.html
} 